Article

\title{
Rainwater Storage Gutters for Houses
}

\section{Mary Hardie}

School of Engineering, University of Western Sydney, Locked Bag 1797, Penrith South, NSW 1797, Australia; E-Mail: m.hardie@uws.edu.au; Tel.: +61-2-4736-0921; Fax: +61-2-4736-8333.

Received: 27 November 2009 / Accepted: 5 January 2010 / Published: 13 January 2010

\begin{abstract}
A history of the implementation of a system of water storage roof gutters illustrates the difficulties which may be encountered in delivering more sustainable construction systems. Utilizing some rainwater at the site where it falls has considerable conservation benefit but it requires builders, roofers and plumbers to vary some of their standard practices. The observed change delivery process involves incorporation of trade knowledge, attention to detail, flexibility and the willingness of all parties including local building control authorities to try new options. Lessons learned have implications for the introduction of many kinds of environmentally driven improvements to domestic construction.
\end{abstract}

Keywords: storage gutters; rainwater use; potable water replacement; infiltration; trade knowledge

\section{Introduction}

Despite an increased tendency towards building high-rise apartments in some major cities, the Australian residential construction sector is still largely low-rise and medium or low density. Individual detached houses, townhouses and villas made up $85 \%$ of residences built in 2001 [1]. The typical housing unit is a three bedroom detached brick veneer with a tiled roof surrounded by lawn and exotic gardens. Such housing is largely being constructed on the periphery of existing cities and is a major consumer of land, water and energy resources. It also has significant adverse impact on the ecology of the surrounding areas [2]. The attraction of such housing, however, remains strong in the Australian population and consequently it is necessary to find ways of minimizing the environmental impact of the traditional ways of building and living in the suburbs. 
Researchers have reported on the need to be more efficient in the use of water in urban situations for some time. Extended droughts in the catchment areas of several major Australian cities in recent years have meant that a strong focus has fallen on the need to minimize the use of piped water in housing. There is also an increasing perception reported in the general news media and the broader research literature that climate change may be leading to generally drier climatic conditions especially in the south eastern portion of the continent. In response, state governments have introduced incentives for householders to collect roof water and use it to substitute for piped water in some situations. The New South Wales government's BASIX scheme requires a 30\% reduction target in household water usage and gives credit to home owners for the installation of rainwater storage devices and water efficient fittings. While this is a welcome development has yet to impact greatly on the existing housing stock [3]. It has long been standard practice in Australia to build houses with pitched roofs where rainwater is collected in roof gutters and passed through downpipes to a local stormwater system which also drains the road surfaces and other hard paved surfaces. The system then passes the stormwater on through pipes of increasing diameter till at some point it is discharged into a canal or waterway. Although this was intended to prevent soil erosion and particularly flooding, the actual result was often an increase in nuisance flooding when drains become blocked with litter and debris. Large areas of hard paved surfaces prevent stormwater naturally infiltrating the soil. When there is no blockage the stormwater picks up considerable kinetic energy through its swift passage down the pipe system and often results in erosion damage at the outlet point into a natural waterway. As a consequence of these effects, modern urban stormwater design seeks to slow down the passage of water through the system by such means as detention ponds, rock baffles and restoring streamside vegetation [4]. In Australia, due to rainfall variability and to state government incentive schemes, there has been a significant and accelerating trend towards including rainwater collection devices in both old and new suburban areas [5,6]. The practice of using rainwater to substitute for piped water supply for some purposes has also been adopted in several parts of the world and in varying climatic conditions [7-16].

A complimentary approach to these efforts has been the innovation of 'roof storage gutters' as rainwater tanks to reduce the input into the stormwater system and replace some of the potable water that is currently used for secondary purposes. Toilet flushing and garden watering do not require drinking quality water though it has been standard practice to waste potable water in this way. Storage gutters replace the use of high quality potable water with rainwater for these secondary purposes. As the gutter is in fact the tank there is no need for large, visually obtrusive rainwater tanks. The drive to improve environmental performance is seen as one of the major drivers of innovation in the construction industry [17,18]. The storyline of the implementation of roof storage gutters has implications for many apparently small modifications of construction practice for sustainability improvements which lead in fact to both downstream and upstream changes in standard practice.

\section{Characteristics of Storage Gutters}

The benefits of this innovation in water storage occur on three levels: the householder, the community and the environment. Firstly, for the householder, there is reduced consumption of mains water supply and resulting lower bills. Little maintenance is required and the gutters have long lives 
due to the leaf guard which ensures no rotting vegetation gets in to the gutter. Less water is needed for the garden because of the associated infiltration system. In medium density attached housing the savings in space on the ground compared to using water tanks can be significant. Secondly, for the community, lower demand on the piped water service means less need for new dams. There is also less need for piped street drainage and area retention systems and consequently lower costs in developing land for housing. Thirdly, for the environment, there is a more natural level of water infiltration into the soil in developed areas and a consequent replenishment of the water table. There may even be a reduction in nuisance flooding and in the erosion hazard of high speed runoff during storms. The system is, however, a departure from standard practice and as such requires a managed change process for its successful adoption.

\subsection{The Ideas behind Storage Gutters}

Roof storage gutters as illustrated in Figure 1 have the advantage of being gravity fed and therefore not requiring pumps to deliver water for household use. Once an installation is adjusted for household usage patterns and exterior landscaping it can continue to function and reduce potable water usage with minimal maintenance or need for other human intervention. A particular advantage that the storage gutters have over rainwater tanks is that because the water is stored at height, gravity feed is available for most applications. Pumps are not required to distribute the water and this avoids additional cost and the possibility of mechanical breakdown. The gutters studied here are produced in three sizes ranging from 15 litres/metre capacity for the small retrofit gutter, to 25 litres/metre for standard applications and 48 litres/metre for heavy demand situations. The gutters are designed to be supported off the roof framing but the large model is sometimes supported off the external wall. They can replace rainwater tanks in suburban areas as they are much less visually obtrusive and take up no floor space on a restricted site. They fit into the standard suburban streetscape in way that large rainwater tanks do not. To date most storage gutter usage has been in standard mass produced housing or 'project homes' and examples in architect designed 'high end' buildings are not available.

Figure 1. Cutaway section of medium sized storage gutter plus diagram showing storage zones.

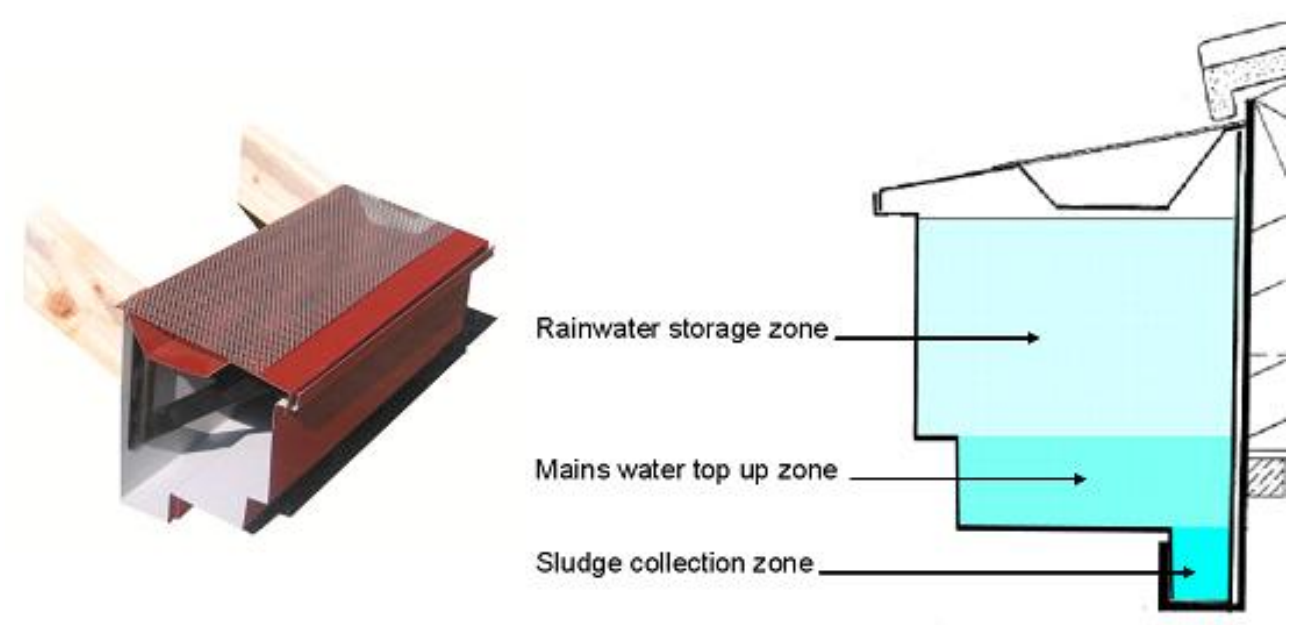


In contrast to traditional gutters which are laid with falls to downpipes the storage gutters need to be laid level for maximum storage capacity. As a result, they collect water from $100 \%$ of the roof area, and not just the plane of roof facing the downpipe. Outlet plugs are installed in the base of the gutters at suitable locations to feed toilet cisterns, washing machines or garden taps. A mains water top up valve is provided to ensure that the water level remains sufficient to feed toilet cisterns even in extensive dry periods. During periods of normal rainfall the storage gutters can replace between $30 \%$ and $60 \%$ of mains water usage, depending on local rainfall distribution, household usage patterns and the collection area of the roof.

\subsection{Infiltration Measures}

An essential ingredient of the concept of storage gutters is that as well as storing water for later use they should redirect overflow to infiltrate the soil and replenish the water table. Each installation of storage gutters and/or tanks requires careful consideration of rainfall patterns and occupant usage levels compared with the area of roof available for collection and the site area available to disperse the overflow. In all installations the soil characteristics are tested to determine the absorptive area needed to cope with the anticipated run-off once the storage gutters are full. A measure of the infiltration level needed can be calculated in the following manner:

$$
\mathrm{Di}=\underline{\mathrm{A} \times \mathrm{S}+\mathrm{IA} \times \mathrm{S}}
$$

IA

where:

$\mathrm{Di}$ is the height of the column of water to be infiltrated by seepage area in metres

$\mathrm{A}$ is the roof area in $\mathrm{m}^{2}$

$\mathrm{S}$ is the 100 year design storm for the location in $\mathrm{m} / \mathrm{hr}$

IA is the seepage or infiltration area available in $\mathrm{m}^{2}$

This yields a column height of water which must be infiltrated [19]. A simple test is then done on site. An infiltrometer is driven into the soil to a level of at least the height of the column of water calculated for the location. The infiltrometer consists of a $400 \mathrm{~mm}$ plastic pipe with inner galvanized steel sleeve at the end that penetrates the ground. The pipe contains an inner plastic tank with four $3 \mathrm{~mm}$ small holes in the bottom surface. A light shower of water is delivered from the holes to the ground. The required volume of water to simulate the amount of rainfall received in one hour of the 100 year design storm for the area is allowed to fall on the ground surface. A site passes the test if all the water has been absorbed and there is no visible surface ponding after 24 hours. Since the storage gutters retain the first flush of any rainfall event there is a considerable built in safety factor in designing for infiltration areas to be able to cope with the runoff from a design storm of one in one hundred years intensity. Estimates have been made of the potential displacement that the gutters can provide in Australian cities based on rainfall averages collected over the pass hundred years. These figures are shown in Table 1. Of course decreased rainfall due to climate change would lessen the impact of the gutters and the savings that can be achieved. At the same time, however, decreased rainfall makes the gains made from any efficiency more significant. 
Table 1. Estimated potential displacement of reticulated water with rainwater from storage gutters in Australian cities.

\begin{tabular}{lc}
\hline Location & $\begin{array}{l}\text { Estimated potable water replacement } \% \text { for } \\
\text { a } 200 \mathrm{~m}^{2} \text { house with average occupancy patterns }\end{array}$ \\
\hline Adelaide & $45 \%$ \\
Brisbane & $50 \%$ \\
Canberra & $34 \%$ \\
Darwin & $40 \%$ \\
Hobart & $50 \%$ \\
Melbourne & $60 \%$ \\
Perth & $50 \%$ \\
Sydney & $55 \%$ \\
\hline
\end{tabular}

(Source: John Argue, Urban Water Resources Centre, University of South Australia).

\section{History of Implementation}

The success of any new idea in construction is very dependent on achieving the cooperation of tradesmen and others who work in associated areas and are partially affected by the changes required. The result of this interdependence is that construction innovations which appear to involve changes to a single component in the building process often have essential flow over effects on surrounding trade practice. The management of the interaction between a green building innovation proposed by a designer and the tradesmen who implement it can become even more important than the value of the innovative idea itself. Certainly the diffusion of the innovation into general industry practice will not occur without 'winning the argument for change' with all the stakeholders. This inertia is an essential characteristic of craft-based traditional construction, and cannot be ignored if construction is to lift its environmental performance. An example is presented of the introduction to the Australian residential construction industry of an innovative system for handling stormwater from roofs. The difficulties encountered elucidate the process of construction innovation and indicate some of the necessary conditions for the diffusion of a sustainable building idea.

A study of 23 early installations was made. The early installations of the storage gutters were carried out by small individual house builders and by a large project home company. Several difficulties were encountered due to the departure the gutters represented from standard practice. Table 2 reports on some of the difficulties experienced with the early cases of storage gutter installations in the late 1990s. Figure 2 illustrates some of the detailing involved in making the installation work correctly.

Because traditional quad and fascia gutters are laid to a fall of between 1 in 100 and 1 in 20 it is not essential that the fascia board or the roof edge be strictly level. In fact, fascia boards are usually not level and this is not apparent with ordinary gutters because the fall in the gutter acts to camouflage irregularity. Storage gutters, however, need to be laid absolutely level for their full storage capacity to be achieved. This means that lower tolerances and a higher level of workmanship are required from the roof framers and roof cladding installers. This was not always immediately apparent when builders first agreed to fit the storage gutters to houses under construction. This presents an even greater 
difficulty when the gutters are retrofitted to existing houses where the fascia boards and roof edge are likely to be slightly out of level, resulting in unsightly gaps between the roof edge and the gutter top at some points.

Table 2. Problems experienced with the early delivery of storage gutter innovation.

\begin{tabular}{|c|c|c|c|c|c|}
\hline \multirow[b]{2}{*}{ Problem } & \multicolumn{4}{|c|}{ Problem caused by } & \multirow[b]{2}{*}{ Remedy } \\
\hline & $\begin{array}{l}\text { Preceeding } \\
\text { trade }\end{array}$ & $\begin{array}{l}\text { Storage } \\
\text { gutters }\end{array}$ & $\begin{array}{l}\text { Following } \\
\text { trade }\end{array}$ & $\begin{array}{l}\text { Occupant } \\
\text { usage }\end{array}$ & \\
\hline $\begin{array}{l}\text { Gaps between roof } \\
\text { edge and gutter top }\end{array}$ & $X$ & & & & $\begin{array}{l}\text { Adjustable brackets to enable the storage } \\
\text { gutters to be laid level around the whole roof. } \\
\text { Advice to builders of the importance of } \\
\text { maintaining level edge around roof. }\end{array}$ \\
\hline $\begin{array}{l}\text { Gutters leaking at } \\
\text { joints }\end{array}$ & & $\mathrm{X}$ & & & $\begin{array}{l}\text { Internal painted-on waterproofing plus silicon } \\
\text { seal at joints. Roll form rather than fold gutters } \\
\text { for greater accuracy of shape therefore fewer } \\
\text { leaks at mitred joints. }\end{array}$ \\
\hline $\begin{array}{l}\text { Gutters overflow at } \\
\text { inappropriate points }\end{array}$ & & $X$ & & & $\begin{array}{l}\text { Overflow holes not to be situated at doorways } \\
\text { or projecting windows. Generally downpipes } \\
\text { and spreaders to be preferred to overflow holes. }\end{array}$ \\
\hline $\begin{array}{l}\text { Water stains on } \\
\text { eaves lining }\end{array}$ & & $\mathrm{X}$ & $\mathrm{X}$ & & $\begin{array}{l}\text { Drip mould formed in gutter or at edge of eaves } \\
\text { lining. Gutter to be positioned with bottom } \\
\text { surface below the edge of the eaves lining. }\end{array}$ \\
\hline $\begin{array}{l}\text { Toilet cisterns not } \\
\text { filling quickly } \\
\text { enough }\end{array}$ & & & $\mathrm{X}$ & & $\begin{array}{l}\text { Larger diameter pipes for inlet to toilet cistern } \\
(18 \mathrm{~mm} \text { no } 12 \mathrm{~mm}) \text {. Plumbers are not to use } \\
\text { pipe sizes they would use for mains pressure } \\
\text { water service. }\end{array}$ \\
\hline $\begin{array}{l}\text { Top up valve not } \\
\text { functioning } \\
\text { correctly, sometimes } \\
\text { failing to shut off }\end{array}$ & & $\mathrm{X}$ & $\mathrm{X}$ & & $\begin{array}{l}\text { Cut-off valve to be position along rather than } \\
\text { across the gutter. }\end{array}$ \\
\hline $\begin{array}{l}\text { Sludge cleanout } \\
\text { messy and } \\
\text { unpleasant }\end{array}$ & & & & $X$ & $\begin{array}{l}\text { Instructional information to be provided for } \\
\text { occupant. Careful positioning of plug for } \\
\text { flushing sludge trap with a garden hose. }\end{array}$ \\
\hline $\begin{array}{l}\text { Insufficient soft } \\
\text { surface area } \\
\text { for infiltration }\end{array}$ & & & $\mathrm{X}$ & $\mathrm{X}$ & $\begin{array}{l}\text { Occupant to be made aware of the need for soft } \\
\text { surface areas to absorb run-off. Restrictions on } \\
\text { percentage site areas that can be hard paved. }\end{array}$ \\
\hline $\begin{array}{l}\text { Mosquito infestation } \\
\text { in gutters }\end{array}$ & & & & $\mathrm{X}$ & $\begin{array}{l}\text { This is only a problem if the house is } \\
\text { unoccupied for long periods during a drought. } \\
\text { Normally the constant movement of the water } \\
\text { through the system would prevent infestation. } \\
\text { If the house is unoccupied arrangements need } \\
\text { to be made for periodic charging of the system. }\end{array}$ \\
\hline
\end{tabular}


Figure 2. Gutter section showing downpipe and fixing brackets.

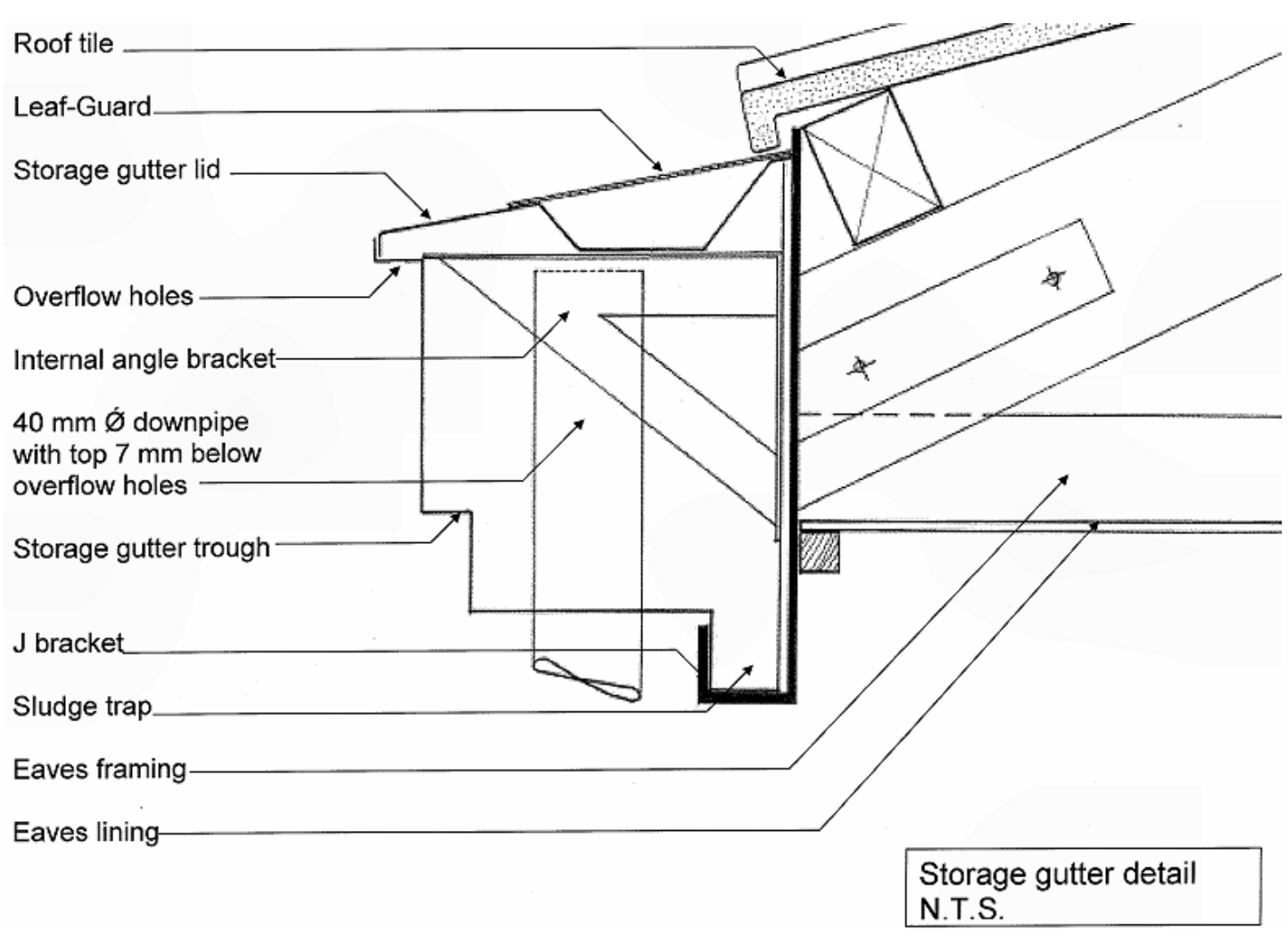

This quality issue was dealt with in two ways. Firstly, it was necessary to ensure that builders were well informed on the system requirements before installation commenced. Indeed it was necessary to insist that they address the issues, given that some tradesmen appear to operate on the principle of 'when all else fails, read the instructions'. Secondly, customized gutter brackets were designed which allowed for accurate adjustment to level during installation.

In the earliest installations, the top lip of the gutter contained perforations which acted as overflow holes to allow rainfall after the initial storm surge to be returned to the garden. This proved to be unsuitable in several instances. In reactive soils it is inappropriate to alternately wet and dry out the soil immediately adjacent to the footings and, indeed, some local government regulations forbade the practice. In addition, overflow holes over doorways or projecting windows gave unsatisfactory results. This practice was modified by adding downpipes and spreaders which allowed controlled infiltration to garden beds (see Figures 2 and 3).

Further issues arose with the plumbers who connected the storage gutters to toilet cisterns or garden taps. These tradesmen tended to use the same size pipe that they would fit for a mains pressure water service to the same outlet (even if larger pipes had been specified). However, since the water was delivered by gravity feed rather than at mains pressure, it was discovered that toilet cisterns took too long to fill up. They could even run dry at times of high usage which proved to be very unsatisfactory for the occupants. It was necessary to get the involvement and compliance of the plumbers in selecting the right capacity pipe for this new installation instead of allowing them to carry on with their standard practice in the face of new requirements (Figure 4). 
Figure 3. Downpipes and diffusers in landscaped garden area.
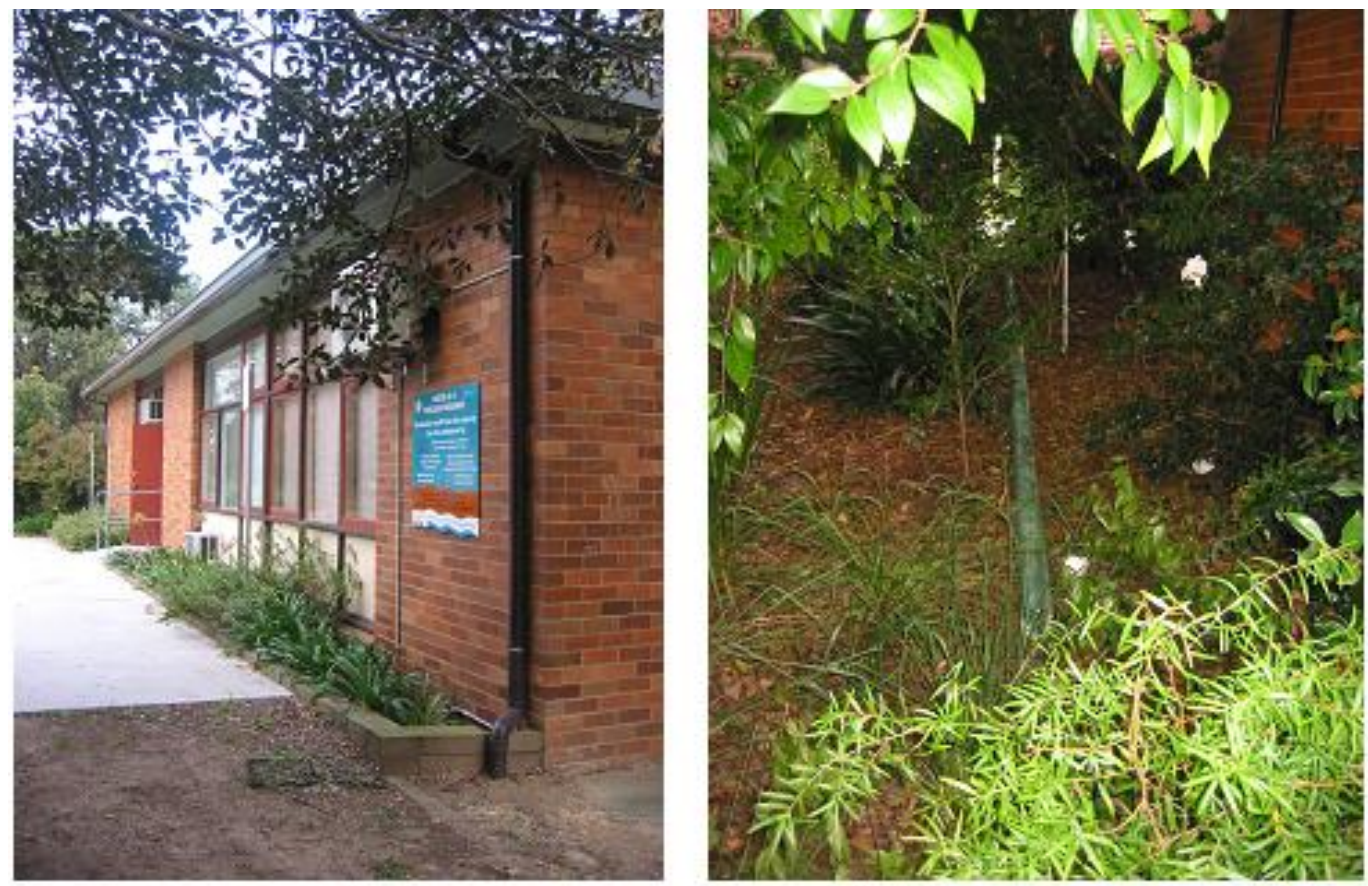

Figure 4. Storage gutter serving pipes to toilet cisterns in a community centre retrofit.
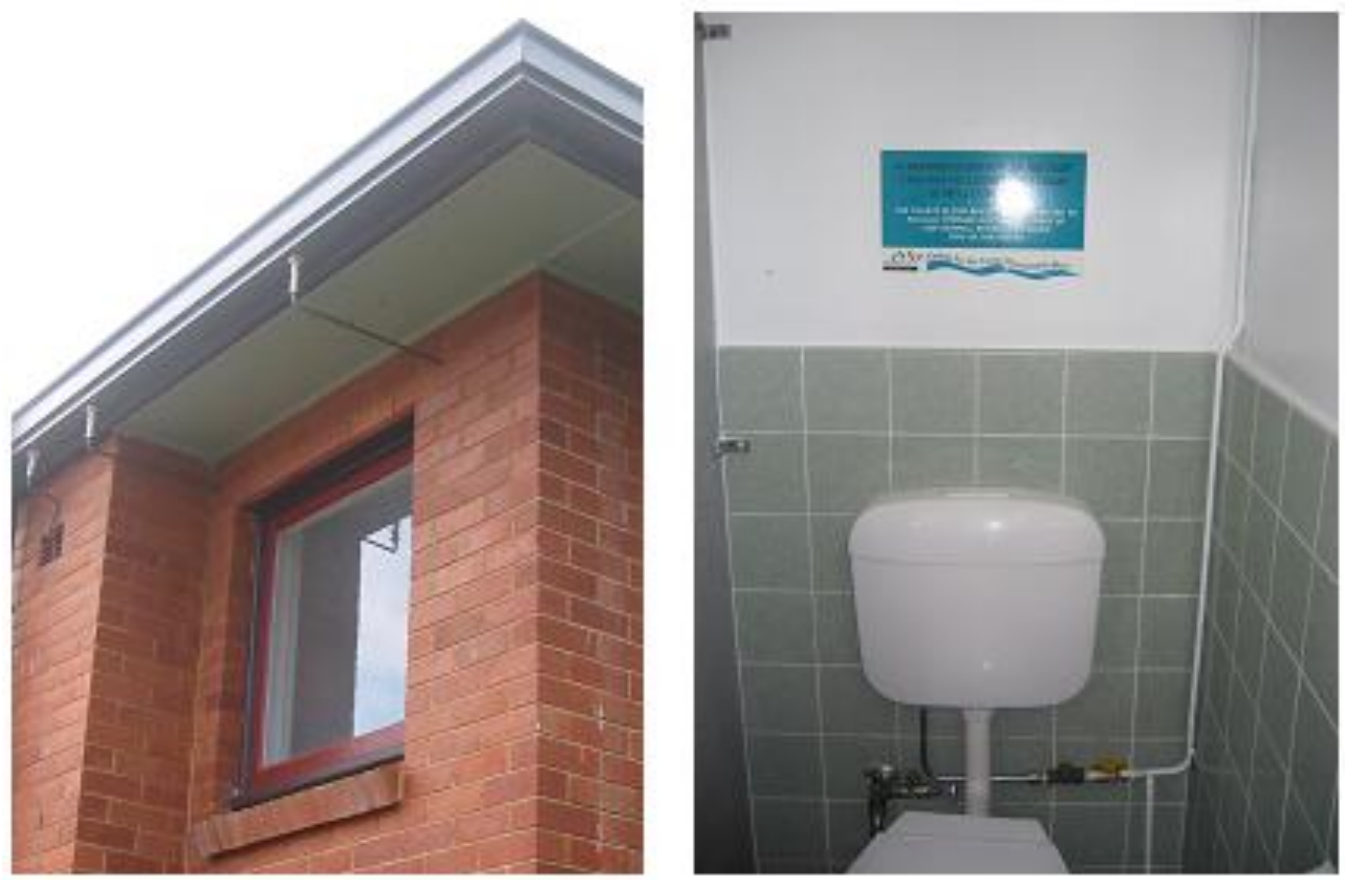

Residential construction is essentially a collaborative exercise. The project-based and powerdistributed nature of construction means that innovations often "spill over" beyond the boundaries of the initial idea [20]. The management of this spill over effect can be the difference between success and failure for a construction innovation. It has been noted, construction workers have considerable informal involvement in the delivery of new products and systems and as a result their cooperation is essential for changed processes to be effectively delivered [21]. Successful technological change in 
construction usually involves an iterative process between designer and practitioner. A good idea will not be accepted without correspondingly good delivery.

\subsection{Occupants’ Experience}

Once the construction problems have been ironed out there may still remain difficulties in the operation of the system by the end user. Environmentally sustainable innovations that involve a mismatch with the existing system, may be blocked simply because users are not accustomed to the new innovation [22]. There needs to be a learning and socialization process in the community for the innovation to be accepted. It is particularly critical that occupants understand the way that the system works so that they do not modify the landscaping or the gutters themselves in unsuitable ways.

Figure 5. Typical installations in Sydney suburbs.
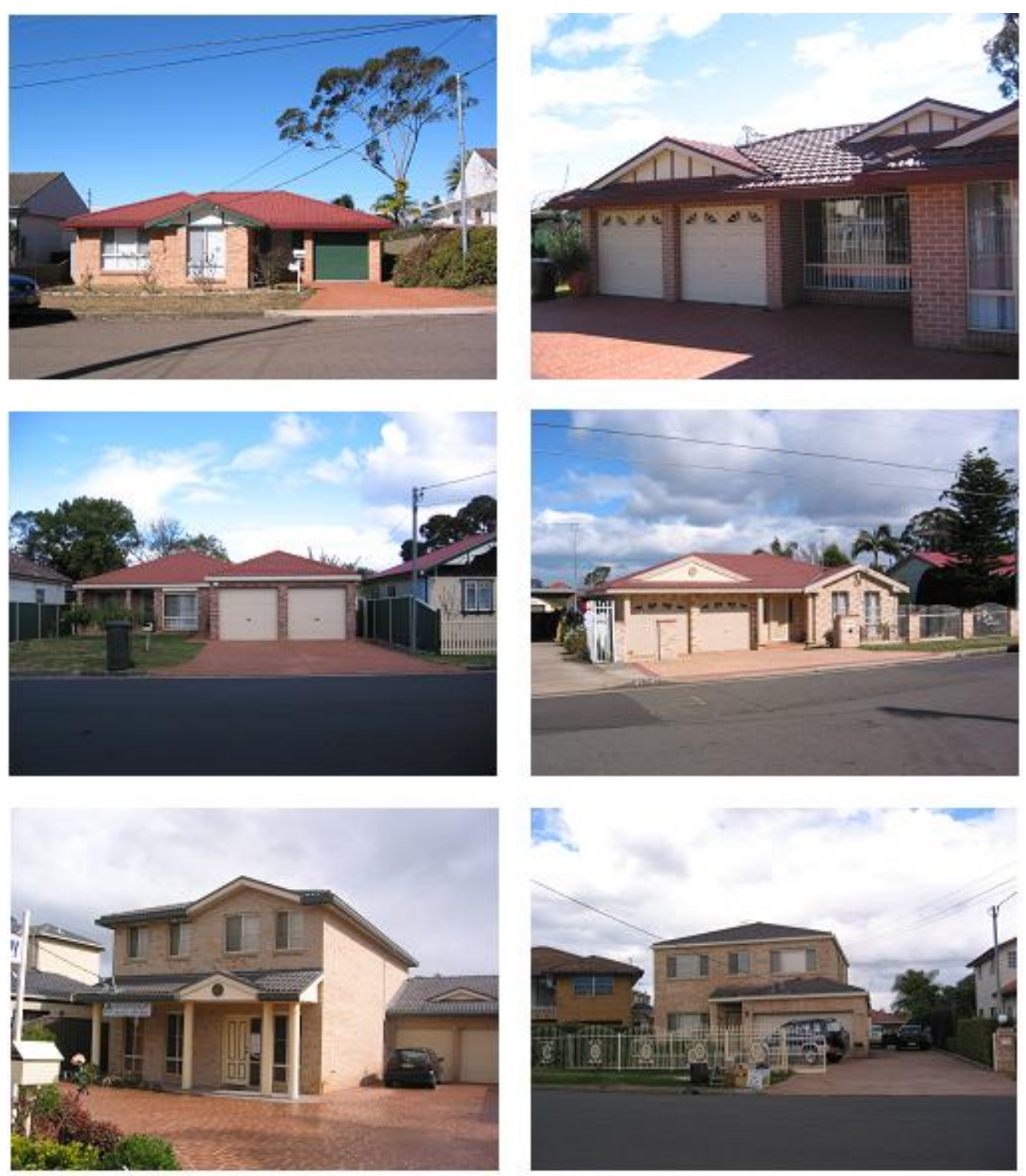
Observation of 23 early roof storage gutter installations in one local government area in Sydney has revealed the difficulties involved in implementing an innovation that involves introducing a non-standard practice to the general public (see Table 1 and Figure 5). Many householders have little or no knowledge of basic construction and maintenance issues and they simply expect a new house to function well without any significant intervention on their part. While this may generally be a not unreasonable expectation, there are times when a certain amount of ongoing maintenance is critical to the continued good operation of building services. The occupant needs to have a basic understanding of how systems work in order that problems are recognized at a stage where they can be easily corrected. This concept is understood with motor cars and few people would fail to be aware of the need for a maintenance and adjustment regime to support the proper functioning of their motor vehicle, however, this need is often not appreciated with a house.

The storage gutters are fitted with leaf-guard to prevent blockage from large quantities of leaf litter but the design also involves the need for occasional flushing out of fine debris which collects in the bottom fold of the gutter. Some residents reported considerable annoyance at this task and rejected the system because of it. The early installations with a full circle of the infiltration holes in the lip of the gutter also provoked occupant's ire because during heavy rain they sent curtains of water down in front of doorways and projecting or bay windows. This is illustrated in Figure 6.

Figure 6. Curtain of water from overflow holes and splash line on wall.
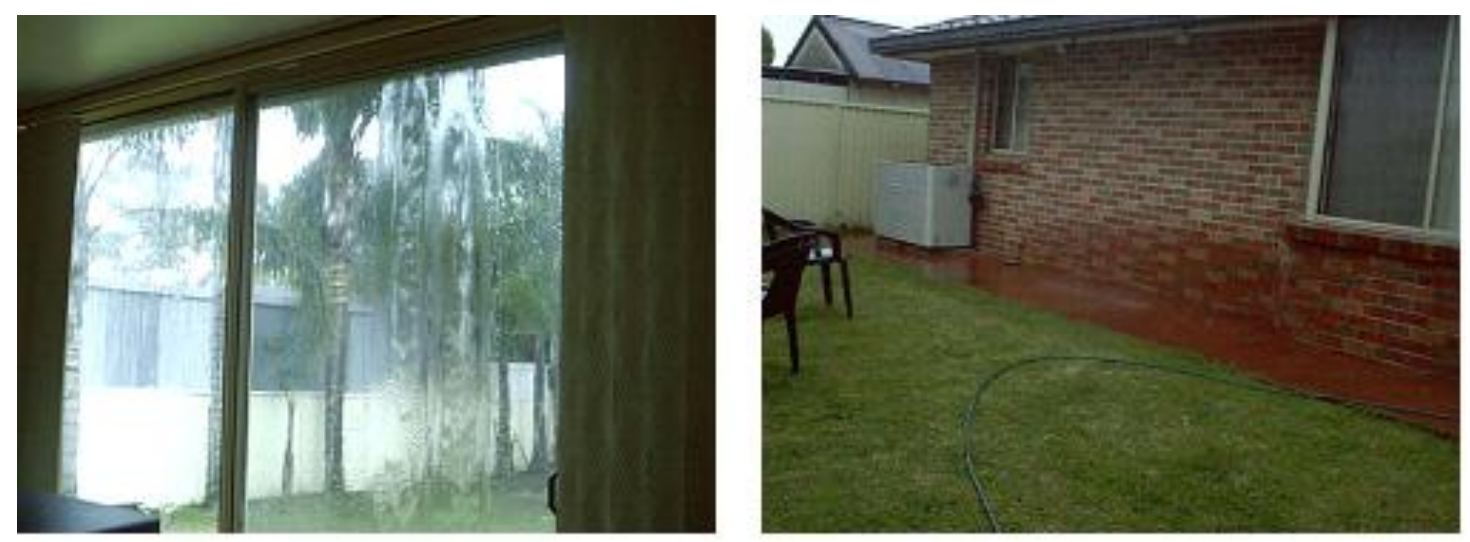

An example of poor understanding of a new system by an owner/occupier is illustrated below in Figure 7. Undersized pipes were used to feed to the toilet cistern. When the resident threw a party the cisterns failed to fill quickly enough at peak usage and the toilet would not flush leading to embarrassment for the host. Instead of fitting larger inlet pipes, his response was to reconnect the cistern to the reticulated water service and cut a hole in the storage gutter fitting a pipe leading to a plastic barrel. The collected water was used to hand water mango trees in the front yard. This was working successfully during the drought period when it was installed but is likely to result in considerable flooding problems when heavy rain eventually falls. 
Figure 7. User modification to storage gutters.
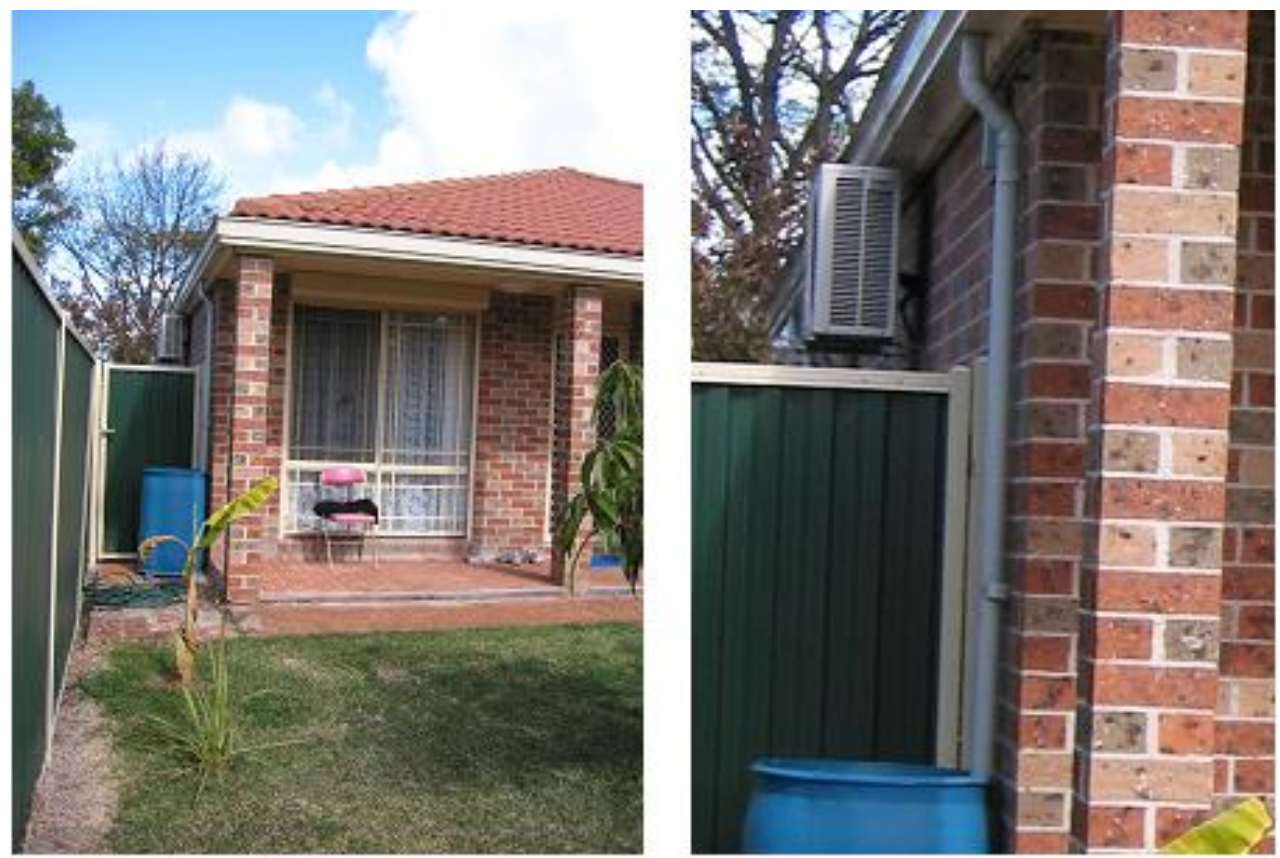

Further complaints were expressed about the gutters leaking at the joints, overflows running back along the face of the gutter resulting in staining of the eaves lining and top up valves failing to cut off. These complaints amount to simple quality control issues which result from the tradesman installing the gutters being unfamiliar with the system. They are now being addressed by more stringent specification of methods and materials to be used, as well as by training of the tradesmen involved by the gutter supplier. In addition, a training module has been prepared for the trade training course for roof plumbers, to ensure that future workers will be familiar with the requirements and properties of the system. The 23 houses observed for this report were all early installations of storage gutters in the late 1990s. Current installations have largely overcome the problems described through information programs and better quality control.

\section{Recommendations}

Wider use of training packages for tradesmen and handymen who install roof gutters could go a long way to preventing several of the problems experienced in the cases studied. It is also important that householders are provided with information about the potential problems so that they know what to do when they encounter difficulties. Mostly the measures required needed to avoid these problems involve little or no extra cost. The cost of slightly larger service pipes from the gutters to the toilet cisterns or washing machines is negligible. Ongoing maintenance of the storage gutters by occasional flushing of any collected debris is also a negligible cost and something that most householders are able to carry out as part of their regular maintenance regimes. It is, however, necessary that this is understood from the start by the occupier of the house with a storage gutter installation. Increasingly, owner manuals are provided with new houses as they have long been with new cars. This is a way of ensuring that regular maintenance is carried out and major problems are avoided. 


\section{Conclusions}

It is of vital importance that the housing sector in Australia and countries where the conservation of water is increasingly critical in the face of potential climate change, develop systems for water efficiency which reduce reliance on new dams and large scale community water supply. Pressure on existing resources is growing with the rise in suburban affluence, and global warming may threaten expected rainfall levels in existing catchments. The storage gutter system represents an attempt to reduce suburban household dependence on piped water supply by using rainwater for some non potable uses in a systematic way. The system is compatible with, but separate from, grey water reuse. If the installation is done correctly and if the system is properly maintained it can result in significant savings in water charges for the householder, reduced infrastructure costs for the community while at the same time reducing the environmental impact of residential development in areas of moderate or erratic rainfall. The idea has the potential to make a significant contribution towards a more sustainable management regime for water resources in suburban areas.

Unfortunately, the process of delivering a new idea to the established residential construction industry is likely to be fraught with difficulty. This is especially true when the idea or innovation is at first glance only a minor modification of existing practice. In these circumstances tradesmen tend to think they need no special instruction or training about something with which they are already familiar. In the case of storage gutters instances were observed where plumbers chose to ignore instructions about pipe sizes from the gutter supplier because they believed their standard practice overrode such instructions. Construction innovations, particularly those with environmental benefits, need to be carefully explained to all those involved in their delivery or they are likely to fail to meet their goals. The potential of the human factor to interfere with the achievement of environmental efficiencies cannot be lightly set aside. In addition, when the construction industry has absorbed the purpose and potential of the idea, there still remains the end users who need to know how the system works and how it may be adjusted for their special circumstances. Otherwise they may make inappropriate adjustments or reject the system out right.

The story of the early implementation of the innovative storage gutter system has lessons for other ideas which seek to modify housing industry practice in order to achieve more sustainable development. New ideas need to be carefully tested by the trades who will put them into practice and their preceding and following trades. Understanding should not be assumed and the idea should have all its features explicitly explained. In addition, an awareness campaign among end users should be considered. Failure to take an inclusive approach to the delivery of the innovation is likely to result in underperformance and unsuccessful diffusion of the system throughout the industry as a whole.

\section{Acknowledgements}

The author would like to thank the Australian Cooperative Research Centre for Construction Innovation for supporting this research. Frank Smith of Rainsaver Australia Pty Ltd is the inventor of the system discussed and was very helpful in providing information and access to storage gutter installations. 


\section{References and Notes}

1. Australian Social Trends-Housing-Housing Stock: Changes in Australian Housing; ABS Catalogue NO. 4102.0; Australian Bureau of Statistics: Canberra, Australia, 2003.

2. Walsh, C.J. Urban impacts on the ecology of receiving waters: a framework for assessment, conservation and restoration. Hydrobiologia 2000, 431, 107-114.

3. Building Sustainability Index; New South Wales Department of Planning: Sydney, Australia, 2010; Available online: http://www.basix.nsw.gov.au/information/about.jsp (accessed on 4 January 2010).

4. Argue, J.; Pezzaniti, D. Catchment "greening" using stormwater in Adelaide, South Australia. Water Sci. Technol. 1999, 39, 177-183.

5. Coombes, P.J.; Kuczera, G. Analysis of the performance of rainwater tanks in Australian capital cities. In Proceedings of the 28th International Hydrology and Water Resources Symposium, Wollongong, Australia, 10-13 November 2003.

6. Coombes, P.J.; Kuczera, G.; Kalma, J.D.; Argue, J.R. An evaluation of the benefits of source control measures at the regional scale. Urban Water 2002, 4, 307-320.

7. Abdulla, F.A.; Al-Shareef, A.W. Roof rainwater harvesting systems for household water supply in Jordan. Desalination 2009, 243, 195-207.

8. Appan, A. A dual-mode system for harnessing roofwater for non-potable use. Urban Water 2000, 1, 317-321.

9. Chilton, J.C.; Maidment, G.G.; Marriott, D.; Francis, A.; Tobias, G. Case study of a rainwater recovery system in a commercial building with a large roof. Urban Water 2000, 1, 345-354.

10. Fewkes, A. The use of rainwater for WC flushing: the field testing of a collection system. Build. Environ. 1999, 34, 765-772.

11. Herrmann, T.; Schmida, U. Rainwater utilization in Germany: efficiency, dimensioning, hydraulic and environmental aspects. Urban Water 2000, 1, 307-316.

12. Qiang, Z. Rainwater harvesting and poverty alleviation: a case study in Gansu, China. Int. J. Water Resour. Dev. 2003, 19, 569-578.

13. Thomas, T. Domestic water supply using rainwater harvesting. Build. Res. Inf. 1998, 26, 94-101.

14. Villarreal, E.L.; Dixon, A. Analysis of a rainwater collection system for domestic water supply in Ringdansen, Norrköping, Sweden. Build. Environ. 2005, 40, 1174-1184.

15. Yuen, E.; Anda, M.; Mathew, K.; Ho, G. Water harvesting techniques for small communities in arid areas. Water Sci. Technol. 2001, 44, 189-195.

16. Mwenge Kahinda, J.-M.; Taigbenu, A.E.; Boroto, J.R. Domestic rainwater harvesting to improve water supply in rural South Africa. Phys. Chem. Earth 2007, 32, 1050-1057.

17. Bossink, B.A.G. Managing drivers of innovation in construction networks. J. Constr. Eng. Manage. 2004, 130, 337-345.

18. Bossink, B.A.G. Leadership for sustainable innovation. Int. J. Technol. Manage. Sust. Dev. 2007, 6, 135-149.

19. Smith, F. Surface infiltration: test to determine a site's suitability and simple site planning considerations. In Proceedings of the International Conference on Water Sensitive Urban Design-Cities as Catchments, Adelaide, Australia, 21-25 November, 2004. 
20. Harty, C. Innovation in construction: a sociology of technology approach. Build. Res. Inf. 2005, 33, 512-522.

21. Coffey, M.; Langford, D. The propensity for employee participation by electrical and mechanical trades in the construction industry. Constr. Manage. Econ. 1998, 16, 543-552.

22. Hofman, P.S. Embedding radical innovations in society. In Proceedings of the 11th Greening of Industry Network Conference, San Francisco, CA, USA, 12-15 October 2003.

(C) 2010 by the authors; licensee Molecular Diversity Preservation International, Basel, Switzerland. This article is an open-access article distributed under the terms and conditions of the Creative Commons Attribution license (http://creativecommons.org/licenses/by/3.0/). 